Rev. Elev. Méd. vét. Pays trop., 1971, 24 (2): 191-201

\title{
Étude de quelques propriétés physico-chimiques du virus de l'encéphalomyélite porcine malgache
}

\author{
par J. RAMISSE, H. SERRES, P. RASOLOFOMANANA et E. RAKOTONDRAMARY
}

\begin{abstract}
RESUME
Plusieurs propriétés du virus de l'encéphalomyélite porcine malgache sont étudiées, comparativement à celles de souches tchèques. Petite taille, acide ribonucléique, résistance aux solvants organiques et aux $\mathrm{pH}$ acides, stabilisation à la chaleur par le chlorure de magnésium, résistance au désoxycholate de soude et à la trypsine, inhibition par le 5 fluorouracile et synthèse cytoplasmique sont identıques.
\end{abstract}

C'est en 1945 qu'une polioencéphalomyélite contagieuse porcine, identique cliniquement à la maladie de Teschen, fit son apparition à Madagascar. En 1950, LEPINE et ATANASIU (12) établirent l'identité immunologique des virus tchèque et malgache.

Dans ce qui va suivre seront explicités des essais comparatifs entre des souches européennes ${ }^{1}$ ) et des souches malgaches. plus particulièrement en ce qui concerne les propriétés caractéristiques des entérovirus (6).

\section{MATERIEL ET METHODES}

\section{A. LES VIRUS}

Les suspensions virulentes sont représentées par le liquide des cultures cellulaires inoculées et en voie de lyse, centrifugé à faible vitesse pour éliminer les débris de cellules. On notera que le milieu de multiplication virale est celui de SCHWOBEL sans sérum.

Les souches Zabreh et Ludrova sont d'origine tchèque. Les autres sont malgaches.

(1) Obtenues par l'intermédiaire du Dr. JACOTOT, de l'Institut Pasteur de Paris, que nous remercions vivement.
Toutes les souches sont adaptées aux cellules de rein de porcelet en culture. Toutes (sauf la A 41) ont été utilisées entre leur $10^{\mathrm{e}}$ et $20^{\circ}$ passage sur cellules en culture (le plus souvent au voisinage du quinzième, au $41^{\mathrm{e}}$ pour la A 41).

\section{B. CULTURES CELLULAIRES}

Les virus ont été multipliés sur cultures de cellules rénales de porcelet selon la technique décrite par BOURDIN et collab. (3).

\section{TITRAGES DE VIRUS}

Les titrages ont été effectués par la méthode de dilution terminale provoquant un effet cytopathogène.

\section{ETUDES DES PROPRIETES PHYSICOCHIMIQUES}

\section{a) Taille du virus}

Elle a été approchée par filtration sur membranes "millipore" de porosité $50 \mathrm{~m} \mu$.

b) Stabilisation cationique vis-à-vis de la chaleur

Le titre virulent a été comparé après exposition à des températures de $25^{\circ}, 37^{\circ}, 56^{\circ}$ 
de suspension virulente normale et de suspension virulente additionnée de chlorure de magnésium $(\mathrm{M} / 1)$, selon WALLIS et MELNICK (23).

\section{c) Stabilité en milieu acide}

Les virus ont été exposés à des pH de 3,9 et 3,5 obtenus à l'aide d'un tampon citrate - acide citrique, et à $\mathrm{pH} 3$ obtenu par un tampon phosphate - acide citrique.;

Durées d'exposition: de 15 minutes à 2 heures.

d) Résistance aux solvants organiques

On a effectué les épreuves à l'éther (20 p. 100) selon ANDREWES (1) et au chloroforme (10 p. 100) selon MAYR et BÖGEL (15). Une épreuve complémentaire a été faite avec 50 p. 100 d'éther.

\section{e) Résistance au désoxycholate de soude}

Les virus ont été mis en contact pendant 1 heure avec des concentrations de désoxycholate de soude allant de $1 / 10$ à $1 / 640$.

\section{f) Résistance aux enzymes protéolytiques}

Test à la trypsine: 3 parties de suspensions virulentes pour 1 partie de solution de trypsine (titre: 300 ) à 2 p. 1.000 pendant 1 heure à $37^{\circ}$.

Test à la papaïne : Parties égales de suspension virulente et de solution de papaïne (titre : 80 ) à 5 p. 1.000 pendant 1 heure à $37^{\circ}$.

\section{g) Résistance à l'eau de javel}

Des dilutions au-delà du 1/50 d'une eau de javel titrant $13,7 \mathrm{~g}$ de chlore par litre sont mises en contact 1 heure et 2 heures avec les virus.

\section{h) Résistance au sulfate}

\section{d'ammonium (MARAMOROSCH - 14)}

La suspension virulente est traitée par un égal volume de sulfate d'ammonium neutre, saturée, à $+4^{\circ} \mathrm{C}$. Le précipité est centrifugé et repris par un volume égal au 1/100 ou $1 / 50 \mathrm{du}$ volume initial.

\section{i) Purification au Fréon}

Selon LARENAUDIE et collab. (11), on a traité les virus au Fréon 113 dans les proportions suivantes:

- Virus

$100 \mathrm{ml}$

- PBS $50 \mathrm{ml}$

- Fréon 113 $150 \mathrm{ml}$

Passage au mixer ( 5 minutes à $4^{\circ}$ ) centrifugation, élimination du culot (effectuer 3 fois de suite).

\section{j) Concentration par centrifugation}

Ultracentrifugation à $30.000 \mathrm{t} / \mathrm{mn}$. donnant $60.000 \mathrm{~g}$ pendant 3 heures à $+4^{\circ}$. Le culot est resuspendu au 1/100 du volume initial.

\section{E. ETUDE DE L'ACIDE NUCLEIQUE}

\section{Inhibition de la multiplication intracellulaire par des agents chimiques}

\section{A) Par la guanidine}

Selon CROWTHER et MELNICK (7), on a étudié l'action de la guanidine à $100 \mu \mathrm{g} / \mathrm{ml}$ dans le milieu de multiplication, sur la reproduction du virus.

b) Par le 2 a (hydroxybenzol) benzimidazole (H.B.B.)

Selon EGGERS et TAMM (9) le H.B.B. a ćté utilisé, après dilution alcoolique, aux concentrations de 100,250 et $500 \mu \mathrm{g} / \mathrm{ml}$ de milieu. A $500 \mu \mathrm{g} / \mathrm{ml}$ il y a une précipitation.

c) Par le 5 Fluoro Uracile (5 F.U.)

Selon MUNYON et collab. (17), le 5 F.U. a été utilisé aux concentrations de 100 et $200 \mu \mathrm{g} / \mathrm{ml}$ de milieu.

\section{d) Par les pyrimidines halogénées}

5 iodo, bromo, ou fluoro 2' désoxyuridine.

Selon SALZMAN (21) ces pyrimidines halogénées inhibent la replication des virus à ADN, mais non de ceux à ARN.

Les tubes inoculés ont reçu $20 \mu \mathrm{g} / \mathrm{ml}$ de 5 bromo. 2' désoxyuridine. Les virus vaccinal (ADN) et de Newcastle (ARN) ont été utilisés comme témoins.

\section{Action de la Ribonucléase (RNA-ase)}

La ribonucléase à $1 \mathrm{mg} / \mathrm{ml}$ a été mise en contact avec les virus intacts, ou purifiés par le Fréon, ou sensibilisés par la trypsine, pendant 1 heure à $37^{\circ} \mathrm{C}$. 


\section{Extraction de l'acide nucléique}

Elle a été réalisée selon la technique de STROHMAIER (22) par le système diphasique Phénol - Eau.

La technique a été modifiée dans les détails suivants :

- La durée d'extraction est prolongée à 2 heures et faite aux températures variées de $+4^{\circ},+25^{\circ},+37^{\circ}$.

- La précipitation de l'acide nucléique est faite par l'alcool absolu, pour éliminer les traces de phénol, sans utilisation ni d'éther ni d'azote, à $-75^{\circ} \mathrm{C}$ pendant 4 heures.

- La solution hypertonique de STROHMAIER, pour dissolution du précipité d'acide nucléique, a été remplacée par celle de PORTOCALA et collab. (18) au chlorure de sodium, moins toxique.

Ces modifications ont permis, entre nos mains, d'obtenir de meilleurs résultats.

Il est important de faire des témoins notamment "précipité nucléique en solution isotonique " qui doit ne donner aucun effet cytopathogène, pour attester l'absence de tout virus non fractionné par le système Phénol - Eau.

\section{Action de la Ribonucléase sur l'acide nucléique}

La ribonucléase à $1 \mathrm{mg} / \mathrm{ml}$ a été utilisée soit sur la phase aqueuse après extraction au phénol, soit sur la solution hypertonique du précipité obtenu par l'alcool au cours de l'extraction.

La durée d'action a été de 30 minutes à $37^{\circ} \mathrm{C}$.

\section{Caractérisation cytochimique intracellulaire du virus}

Les diverses colorations ont porté sur des cellules rénales infectées (et témoins) cultivées sur des lamelles en tubes. Nous avons appliqué les techniques formulées par LEPINE (13):

- Vert de méthyle - pyronine et test de BRACHET. Fixation des cellules au Carnoy, coloration avec le mélange vert de méthyle (préalablement lavé au chloroforme) et pyronine, différenciation rapide à l'alcool à $70^{\circ}$, rinçage à l'eau. séchage à l'étuve et montage sous huile de paraffine. Pour le test de BRACHET, action de la RNA-ase en solution au $1 / 1.000$ pendant
1 heure à $56^{\circ}$. Puis colorations comme ci-dessus.

- FEULGEN - technique classique.

- Orangé d'acridine - colorant dilué au $1 / 10.000$ en P.B.S.

\section{LES RESULTATS OBTENUS}

\section{A. CONCERNANT LES PROPRIETES PHYSICO-CHIMIQUES GENERALES}

\section{La taille}

Elle est inférieure à $50 \mathrm{~m} \mu$ puisque le filtrat sur membrane "millipore " $(50 \mathrm{~m} \mu)$ conserve encore un pouvoir cytopathogène spécifique.

\section{Stabilisation à la chaleur par le chlorure de magnésium}

Nous avons résumé les résultats des différents essais dans les tableaux 1 et 2 .

Les conclusions de ces tableaux sont que:

- Le comportement à la chaleur du virus local et du virus européen est comparable.

- La protection de ces virus par le $\mathrm{Cl}_{2} \mathrm{Mg}$ contre la dénaturation thermique est certaine; mais plus marquée lors d'une exposition de courte durée à une température plus élevée, que pour une longue conservation à température moins élevée. Cette protection du virus par le $\mathrm{Cl}_{2} \mathrm{Mg}$ n'implique pas le maintien du pouvoir vaccinant selon BOURDIN et collab. (4).

\section{Résistance aux pH acides}

Pour les souches locales examinées, de même que pour la souche Zabreh, il n'y a pas de diminution de titre cytopathogène après traitement de 15 minutes à 2 heures par une acidité plus ou moins marquée: $\mathrm{pH}$ de 3,$9 ; 3,5 ; 3$. Ceci est en accord avec le résultat énoncé par A. MAYR (16) pour le virus de Teschen.

\section{Résistance aux solvants organiques}

Les résultats sont résumés dans le tableau $n^{0} 3$.

Ce tableau nous montre que :

- Les souches sont partiellement sensibles à l'éther (surtout à la concentration de 
TABLEAU $\mathbb{N}^{\circ} \mathrm{I}$

Stabilisation du varus de l'encëphalomyélite porcine par le Cl2Mg/M

\begin{tabular}{|c|c|c|c|}
\hline Souche virale & Tempëratures & $\begin{array}{c}\text { Durée } \\
d^{2} \text { exposition }\end{array}$ & Titre limite \\
\hline $\begin{array}{l}\text { D } 116 \text { (Elanks) } \\
\text { D } 116 \text { (C12Mg) }\end{array}$ & $\begin{array}{l}56^{\circ} \\
56^{\circ}\end{array}$ & $\begin{array}{l}30 \mathrm{mr} \\
30 \mathrm{mr}\end{array}$ & $\begin{array}{l}10^{-6} \\
10^{-8}\end{array}$ \\
\hline $\begin{array}{lll}\text { D } & 116 & \text { (Hanks) } \\
\text { D } & 116 & \text { (C12Mg) }\end{array}$ & $\begin{array}{l}56^{\circ} \\
56^{\circ}\end{array}$ & $\begin{array}{l}1 \mathrm{~h} \\
1 \mathrm{~h}\end{array}$ & $\begin{array}{l}10^{-3} \\
10^{-8}\end{array}$ \\
\hline $\begin{array}{l}\text { D } 116 \text { (Hanks) } \\
\text { D } 116 \text { (C12Mg) }\end{array}$ & $\begin{array}{l}56^{\circ} \\
56^{\circ}\end{array}$ & $\begin{array}{l}2 \mathrm{~h} \\
2 \mathrm{~h}\end{array}$ & $\begin{array}{l}10^{-3} \\
10^{-8}\end{array}$ \\
\hline $\begin{array}{l}\text { D } 116 \text { (Hanks) } \\
\text { D } 116 \text { (C12Mg) }\end{array}$ & $\begin{array}{l}56^{\circ} \\
56^{\circ}\end{array}$ & $\begin{array}{l}4 \mathrm{~h} \\
4 \mathrm{~h}\end{array}$ & $\begin{array}{l}16^{-2} \\
10^{-4}\end{array}$ \\
\hline $\begin{array}{l}\text { Zabreh (Hanks) } \\
\text { Zabreh (C12Mg) }\end{array}$ & $\begin{array}{l}56^{\circ} \\
56^{\circ}\end{array}$ & $\begin{array}{l}30 \mathrm{mn} \\
30 \mathrm{mn}\end{array}$ & $\begin{array}{l}10^{-3} \\
10^{-8}\end{array}$ \\
\hline $\begin{array}{l}\text { Zabreh (Hanks) } \\
\text { Zabreh (C12Mg) }\end{array}$ & $\begin{array}{l}56^{\circ} \\
56^{\circ}\end{array}$ & $\begin{array}{l}1 \mathrm{~h} \\
1 \mathrm{~h}\end{array}$ & $\begin{array}{l}10^{-3} \\
10^{-8}\end{array}$ \\
\hline $\begin{array}{l}\text { Zabreh (Hanks) } \\
\text { Zabreh (Cl.2Mg) }\end{array}$ & $\begin{array}{l}56^{\circ} \\
56^{\circ}\end{array}$ & $\begin{array}{l}2 \mathrm{~h} \\
2 \mathrm{~h}\end{array}$ & $\begin{array}{l}10^{-3} \\
10^{-7}\end{array}$ \\
\hline $\begin{array}{l}\text { D } 116 \text { (Eanks) } \\
\text { D } 116 \text { (C12Mg) }\end{array}$ & $\begin{array}{l}37^{\circ} \\
37^{\circ}\end{array}$ & $\begin{array}{l}10 \mathrm{j} \\
10 \mathrm{j}\end{array}$ & $\begin{array}{l}10^{-3} \\
10^{-4}\end{array}$ \\
\hline $\begin{array}{l}\text { Zabreh (Hanks) } \\
\text { Zabreh (C12Mg) }\end{array}$ & $\begin{array}{l}37^{\circ} \\
37^{\circ}\end{array}$ & $\begin{array}{l}10 j \\
10 j\end{array}$ & $\begin{array}{l}10^{-3} \\
10^{-4}\end{array}$ \\
\hline
\end{tabular}

TABLEAUU $N^{\circ} \mathrm{II}$

Stabllisation du virus local exposé à la chaleur, par le C12Mg/M

\begin{tabular}{|c|c|c|c|}
\hline Souche virale & $\begin{array}{l}\text { Tempếrature } \\
{ }^{\circ} \mathrm{C}\end{array}$ & $\begin{array}{c}\text { Durée } \\
d^{2} \text { exposition }\end{array}$ & $\begin{array}{l}\text { Titre limite } \\
\text { rêsiduel }\end{array}$ \\
\hline $\begin{array}{l}\text { P } 1232 \text { (Schwobe1) } \\
\text { P } 1232 \text { (C 12Mg) }\end{array}$ & $\begin{array}{l}56 \\
56\end{array}$ & $\begin{array}{l}30 \mathrm{mn} \\
30 \mathrm{mn}\end{array}$ & $\begin{array}{l}10^{-7} \\
10^{-8}\end{array}$ \\
\hline $\begin{array}{l}\text { P } 1232 \text { (Schwöbel ) } \\
\text { P } 1232 \text { (cl2Mg) }\end{array}$ & $\begin{array}{l}56 \\
56\end{array}$ & $\begin{array}{ll}1 \mathrm{~h} \\
1 \mathrm{~h}\end{array}$ & $\begin{array}{l}10^{-4} \\
10^{-7}\end{array}$ \\
\hline $\begin{array}{l}\text { P } 1232 \text { (Schwöbe1) } \\
\text { P } 1232 \text { (C1.2Mg) }\end{array}$ & $\begin{array}{l}37 \\
37\end{array}$ & $\begin{array}{ll}1 \mathrm{~h} \\
1 \mathrm{~h}\end{array}$ & $\begin{array}{l}10^{-7} \\
10^{-8}\end{array}$ \\
\hline $\begin{array}{l}\text { P } 1232 \text { (Schwöbe1) } \\
\text { P } 1232 \text { (C12Mg) }\end{array}$ & $\begin{array}{l}37 \\
37\end{array}$ & $\begin{array}{l}6 \mathrm{~h} \\
6 \mathrm{~h}\end{array}$ & $\begin{array}{l}10^{-7} \\
10^{-8}\end{array}$ \\
\hline $\begin{array}{l}\text { P } 1232 \text { (Schwöbel) } \\
\text { P } 1232 \text { (C12Mg) }\end{array}$ & $\begin{array}{l}37 \\
37\end{array}$ & $\begin{array}{l}24 \mathrm{~h} \\
24 \mathrm{~h}\end{array}$ & $\begin{array}{l}10^{-3} \\
10^{-5}\end{array}$ \\
\hline $\begin{array}{l}\text { P } 1232 \text { (Sclwöbel) } \\
\text { P } 1232 \text { (C12Mg) }\end{array}$ & $\begin{array}{l}20 \\
20\end{array}$ & $\begin{array}{l}8 j \\
8 j\end{array}$ & $\begin{array}{l}10^{-3} \\
10^{-5}\end{array}$ \\
\hline $\begin{array}{l}\text { P } 1232 \text { (Schwöbe1) } \\
\text { P } 1232 \text { (C12Mg) }\end{array}$ & $\begin{array}{l}20 \\
20\end{array}$ & $\begin{array}{l}12 \mathrm{j} \\
12 \mathrm{j}\end{array}$ & $\begin{array}{l}10^{-2} \\
10^{-3}\end{array}$ \\
\hline
\end{tabular}




\begin{tabular}{|c|c|c|c|}
\hline \multicolumn{4}{|c|}{ Traitement à $l^{\prime}$ éther à 50 p. 100} \\
\hline Souches virales & $\begin{array}{c}\text { Virus } \\
\text { non traitẽ }\end{array}$ & Virus traité & $\begin{array}{c}\text { Différences } \\
\text { en } \log 10\end{array}$ \\
\hline $\begin{array}{l}\text { Zabreh } \\
\text { A } 41 \\
\text { D } 388\end{array}$ & $\begin{array}{l}10^{-8} \\
10^{-8} \\
10^{-7}\end{array}$ & $\begin{array}{l}10^{-4} \\
10^{-4} \\
10^{-3}\end{array}$ & $\begin{array}{l}4 \\
4 \\
4\end{array}$ \\
\hline \multicolumn{4}{|c|}{ Traitement à l'éther à 20 p. 100} \\
\hline $\begin{array}{l}\text { Zabreh } \\
\text { Ludrova } \\
\text { Locales } \\
\text { P } 1232 \\
\text { D } 423 \\
\text { D } 116 \\
\text { D } 388 \\
\text { D } \quad 57 \\
\text { D } \quad 764 \\
\text { D } 155 \\
\text { D } 457 \\
\text { A } 41 \\
\text { Newcastle (têmoin) } \\
\text { sur cellules K.B. }\end{array}$ & $\begin{array}{l}10^{-8} \\
10^{-7} \\
10^{-8} \\
10^{-8} \\
10^{-8} \\
10^{-8} \\
10^{-8} \\
10^{-7} \\
10^{-7} \\
10^{-7} \\
10^{-8} \\
10^{-8}\end{array}$ & $\begin{array}{l}10^{-6} \\
10^{-5} \\
10^{-7} \\
10^{-6} \\
10^{-6} \\
10^{-5} \\
10^{-5} \\
10^{-3} \\
10^{-4} \\
10^{-3} \\
10^{-2} \\
0\end{array}$ & $\begin{array}{l}1 \\
2 \\
2 \\
3 \\
3 \\
4 \\
3 \\
4 \\
6 \\
8\end{array}$ \\
\hline \multicolumn{4}{|c|}{ Traitement au chloroforme à 10 p. 100} \\
\hline $\begin{array}{l}\text { Zabreh } \\
\text { Locales } \\
\begin{array}{rr}\text { A } & 41 \\
\text { D } & 388 \\
& 2748 \\
& 2784 \\
\text { D } & 214 \\
\text { D } & 300 \\
\text { D } 2736 \\
\text { D } 2933\end{array}\end{array}$ & $\begin{array}{l}10^{-8} \\
10^{-8} \\
10^{-7} \\
10^{-7} \\
10^{-8} \\
10^{-8} \\
10^{-8} \\
10^{-8} \\
10^{-8}\end{array}$ & $\begin{array}{l}10^{-8} \\
10^{-8} \\
10^{-7} \\
10^{-7} \\
10^{-8} \\
10^{-8} \\
10^{-8} \\
10^{-8} \\
10^{-8}\end{array}$ & $\begin{array}{l}0 \\
0 \\
0 \\
0 \\
0 \\
0 \\
0 \\
0\end{array}$ \\
\hline
\end{tabular}

50 p. 100) dans les conditions expérimentales adoptées. Cependant elles y sont moins sensibles que le virus de Newcastle qui. lui, est complètement détruit. La sensibilité augmenterait peut-être au fur et à mesure des passages sur cellules;

- Les souches résistent au chloroforme. Ceci est en conformité avec le travail de A. MAYR (15). Il est donc préférable d'aseptiser les prélèvements à inoculer aux cellules (fécès) par le chloroforme plutôt que par l'éther.

\section{Résistance au désoxycholate de soude}

Les cellules rénales de porc en culture inoculées avec le virus traité par le désoxycholate aux plus fortes concentrations sont lysées par le produit. Par contre, à partir de la dilution au 1/640, le désoxycholate ne lyse plus les cellules. Mais il ne détruit pas le virus local qui lyse les cellules d'une façon spécifique. D'après A.O. BETTS (2) les effets du désoxycholate sur les entérovirus porcins sont variables. Certaines souches seraient inhibées par une concentration au $1 / 1.000$. 


\section{Résistance aux enzymes protéolytiques}

Les titrages exprimés en dose infectieuse limite sont consignés dans le tableau $\mathrm{n}^{\circ} 4$.
Les souches, pour la plupart, résistent au traitement. Certaines auraient leur titre augmenté par le traitement.

TABLEAU $\mathrm{N}^{\circ} \mathrm{IV}$

Iraitement à la trypoine et à la papaīne.

\begin{tabular}{|c|c|c|c|}
\hline Souches virales & $\begin{array}{c}\text { Non traitées } \\
\text { (titre) }\end{array}$ & $\begin{array}{c}\text { Traitées à 1a } \\
\text { trypsine } \\
\text { (titre) }\end{array}$ & $\begin{array}{c}\text { Diffêrences } \\
\text { en } \log 10\end{array}$ \\
\hline Zabreh & $10^{-8}$ & $10^{-7}$ & -1 \\
\hline D 116 & $10^{-6}$ & $10^{-7}$ & +1 \\
\hline D 348 & $10^{-6}$ & $10^{-7}$ & +1 \\
\hline D 57 & $10^{-6}$ & $10^{-7}$ & +1 \\
\hline D 155 & $10^{-6}$ & $10^{-6}$ & 0 \\
\hline D 457 & $10^{-5}$ & $10^{-6}$ & +1 \\
\hline 2748 & $10^{-8}$ & $10^{-8}$ & 0 \\
\hline 2784 & $10^{-8}$ & $10^{-8}$ & 0 \\
\hline D 214 & $10^{-8}$ & $10^{-8}$ & 0 \\
\hline D 300 & $10^{-7}$ & $10^{-7}$ & 0 \\
\hline D2736 & $10^{-8}$ & $10^{-8}$ & 0 \\
\hline D2933 & $10^{-8}$ & $10^{-8}$ & 0 \\
\hline P1232 & $10^{-8}$ & $10^{-3}$ & -5 \\
\hline Souches virales & Non traltées & $\begin{array}{c}\text { Traitées à la } \\
\text { papaIne }\end{array}$ & Diffërences \\
\hline D 457 & $10^{-5}$ & $10^{-6}$ & +1 \\
\hline
\end{tabular}

\section{Résistance à l'eau de javel}

La combinaison des résultats provenant des trois expériences montre que le virus local est détruit par l'eau de javel au 1/50 au bout de 2 heures.

\section{Résistance au sulfate d'ammonium}

Les différents titrages pratiqués sur le virus malgache (5 souches) par précipitation au sulfate d'ammonium donnent des résultats identiques. Si le virus est concentré 100 fois en volume, son titre augmente également 100 fois. Ce qui prouve que le virus résiste à l'action du sulfate d'ammonium. Ce peut être un procédé d'enrichissement du virus, mais non de purification car les protéines du milieu sont aussi précipitées.

\section{Purification par le Fréon 113}

Dans les conditions où nous avons opéré, après le $3^{\text {e }}$ cycle de purification il n'y a plus de précipité visqueux correspondant aux protéines du milieu. Le surnageant de la dernière centrifugation qui contient le virus purifié ne donne aucune bande visible à l'électrophorèse, alors que le virus brut donnait plusieurs bandes. Le virus purifié possède un titre cytopathogène assez bas, en général inférieur de 2 à 3 logs à celui du virus brut. Cette perte au cours de la purification a été signalée pour d'autres virus [LARENAUDIE (11) virus de la peste porcine africaine]. Ce virus purifié, quoique de faible titre, peut servir pour l'immunisation d'animaux si l'on désire produire des anticorps spécifiquement antiviraux, sans anticorps anticellulaires. 


\section{Enrichissement par centrifugation à grande vitesse}

La concentration d'une souche malgache après une centrifugation à $30.000 \mathrm{t} / \mathrm{mn}$ pendant 3 heures est du même ordre que celle obtenue par précipitation au sulfate d'ammonium. Si le volume est diminué 100 fois, le titre est augmenté d'autant. Le titrage a été fait sur cellules. En effet, le dosage spectrophotométrique n'a pas donné de résultats significatifs, la concentration du milieu en virus étant trop faible par rapport à la quantité de protéines étrangères dans les conditions habituelles de l'expérimentation.

\section{B. ETUDE SUR L'ACIDE NUCLEIQUE}

\section{Sensibilité aux inhibiteurs chimiques}

\section{a) Guanidine}

A la concentration de $100 \mu \mathrm{g} / \mathrm{ml}$ dans le milieu d'entretien, la guanidine n'empêche pas la replication de 15 souches locales ni des 2 souches tchèques dont nous disposons (Zabreh et Ludrova). Ce résultat rejoint celui obtenu par PORTOLANI (19) avec les entérovirus bovins. Par conséquent, l'action inhibitrice de la guanidine ne semble pas générale, mais plutôt spécifique à un certain nombre d'entérovirus.

b) 2 ( $\alpha$ hydroxybenzyl)

benzimidazole ou 2 a H.B.B.

L'effet du $2 \alpha$ H.B.B. sur les entérovirus est, comme celui de la guanidine, variable selon les souches. Certains entérovirus bovins y sont sensibles (PORTOLANI - 19) - (BUCZEK 5). Selon RASMUSSEN (20), les entérovirus porcins ne sont pas sensibles à une concentration de $219 \mu \mathrm{M} / 1$. DARDIRI et collab. (8) ont observé un effet inhibiteur, variable selon la concentration en H.B.B. sur les virus Teschen et ECPO. Par contre HAHNEFELD et collab. (10) n'ont pas constaté une nette réduction du titre et de l'E.C.P. du virus Talfan en utilisant le H.B.B. aux concentrations de 50 à $200 \mu \mathrm{g} / \mathrm{ml}$.

Nous avons utilisé le 2 a H.B.B. aux concentrations de $100,250,500 \mu \mathrm{g} / \mathrm{ml}$ dans le milieu d'entretien. A $500 \mu \mathrm{g} / \mathrm{ml}$, le produit est toxique Dour les cellules. A 100 et $200 \mu \mathrm{g} / \mathrm{ml}$, pour les 3 souches locales étudiées, nous n'avons pas observé d'effet inhibiteur.

\section{c) 5 fluoro-uracile (5-FU)}

A la concentration de $100 \mu \mathrm{g} / \mathrm{ml}$ et au premier passage, il y a baisse de titre de $1 \log$ à condition de diluer le virus pour l'adsorption dans le milieu d'entretien contenant le 5-FU. Au deuxième passage, avec une concentration de $250 \mu \mathrm{g} / \mathrm{ml}$ de $5-\mathrm{FU}$, il y a une chute considérable du titre. Le virus ne lyse que s'il est inoculé pur. Un premier passage en présence de $250 \mu \mathrm{g} / \mathrm{ml}$ de 5 -FU fait apparaître une chute de titre correspondant à 2 ou 3 logs. Il semble donc que le 5-FU inhibe partiellement le virus de l'encéphalite porcine, cette inhibition s'accentuant avec les passages.

Cette inhibition est un argument en faveur de la nature ribonucléique de l'acide nucléique car le 5-FU est un analogue de l'uracile, base pyrimidique entrant dans la composition du RNA. Le 5-FU entrave donc la formation du RNA viral.

\section{d) Pyrimidines halogénées}

Ces composés bloquent l'incorporation de la thymidine dans l'ADN et empêchent la formation de l'ADN, mais non de l'ARN. C'est ainsi qu'ils empêchent la replication du virus vaccinal sur cellules rénales de lapin, mais non la multiplication du virus de Newcastle sur cellules K.B.

Dans notre expérimentation, la bromo-désoxyuridine à la concentration de $20 \mu \mathrm{g} / \mathrm{ml}$ n'inhibe pas du tout la replication de 8 souches locales ni des 2 tchèques, ni du témoin Newcastle, alors qu'elle bloque complètement le témoin vaccinal.

Ce résultat confirme celui obtenu avec le 5-FU et nous permet d'affirmer, d'ores et déjà, que les virus locaux de l'encéphalomyélite porcine contiennent de l'acide ribonucléique. Il en est de même, d'ailleurs, pour les souches tchèques.

\section{Action directe de la RNA-ase sur le virus}

De ce tableau $n^{\circ} 5$, il ressort que la RNA-ase est absolument inactive sur le virus intact, sur le virus purifié au Fréon, ou traité à la trypsine.

\section{Extraction de l'acide nucléique}

Nous résumons dans le tableau $\mathrm{n}^{\circ} 6$ les résultats obtenus. 


\begin{tabular}{|c|c|c|c|c|c|}
\hline $\begin{array}{l}\text { Souches } \\
\text { virales }\end{array}$ & $\begin{array}{l}\text { Purification } \\
\text { au fréon }\end{array}$ & $\begin{array}{l}\text { Action de } \\
\text { la trypsine }\end{array}$ & $\begin{array}{l}\text { RliA-ase } \\
1 \mathrm{mg} / \mathrm{ml}\end{array}$ & Température & $\begin{array}{r}\text { Titre } \\
\text { limite }\end{array}$ \\
\hline D 116 & - & - & + & 25 & $10^{-8}$ \\
\hline D 116 & - & - & + & 37 & $10^{-7}$ \\
\hline D $\quad 57$ & - & - & + & 37 & $10^{-8}$ \\
\hline $\mathrm{TD} \quad 9$ & + & - & - & & $10^{-5}$ \\
\hline $\mathrm{TD} \quad 9$ & + & - & + & 37 & $10^{-5}$ \\
\hline $\mathrm{TD}$ & + & - & - & & $10^{-5}$ \\
\hline TD 7 & + & - & + & 25 & $10^{-5}$ \\
\hline D 116 & - & + & - & & $10^{-8}$ \\
\hline D 116 & - & + & + & 37 & $10^{-8}$ \\
\hline
\end{tabular}

TABLEAU $\mathbb{N}^{\circ} \mathrm{VI}$

Extraction de l'acide nuclêique

\begin{tabular}{|c|c|c|c|c|c|c|}
\hline $\begin{array}{l}\text { Titre limite } \\
\text { du varus } \\
\text { intial }\end{array}$ & $\begin{array}{l}\text { Phénol aqueux } \\
\text { v de phênol } \\
\text { v d'eaul }\end{array}$ & \multicolumn{2}{|c|}{$\begin{array}{l}\text { Température } \\
\text { et durée } \\
\mathrm{d}^{\text {'extraction }} \\
{ }^{\circ} \mathrm{C} \quad \text { heure }\end{array}$} & $\begin{array}{r}\text { Solution hypertonique } \\
3 \text { pour dissolution de } \\
1 \text { 'extrait=est à base de: }\end{array}$ & $\begin{array}{l}\text { ler passage } \\
\text { Résultat- } \\
\text { titre }\end{array}$ & $\begin{array}{l}\text { 2è passage } \\
\text { pour confirmer } \\
\text { la spëciflcitế }\end{array}$ \\
\hline $10^{-7}$ & $1 / 1$ & 4 & 1 & $\mathrm{KCl}$ (Strohmaier) & $\begin{array}{l}\text { Nëgatif } \\
\text { (5 fois) }\end{array}$ & \\
\hline $10^{-B}$ & $2 / 1$ & 4 & 1 & $\mathrm{KCl}$ & $\begin{array}{l}+(1 \text { fois }) 10^{-2} \\
-(1 \text { fois })\end{array}$ & + \\
\hline $10^{-7}$ & $1 / 1$ & 4 & 1 & $\mathrm{KC} 1$ & $+(3$ fois $) 10^{-1}$ & + \\
\hline $10^{-7}$ & $5 / 1$ & 4 & 1 & $\mathrm{KC} 1$ & - & \\
\hline $10^{-9}$ & $9 / 1$ & 4 & $3 / 4$ & KC1 & - & \\
\hline $10^{-9}$ & $9 / 1$ & 4 & 1 & NaC1 (Portocala) & $+10^{-2}$ & + \\
\hline $10^{-8}$ & $9 / 1$ & 4 & $1 / 2$ & $\mathrm{NaCl}$ & $\begin{array}{l}+(1 \text { fois }) 10^{-1} \\
-(1 \text { fois })\end{array}$ & + \\
\hline $10^{-8}$ & $9 / 1$ & $\begin{array}{l}25 \\
37\end{array}$ & $\begin{array}{l}1 \\
1\end{array}$ & $\begin{array}{l}\mathrm{NaC1} \\
\mathrm{NaC1}\end{array}$ & $\begin{array}{ll}+ & 10^{-2} \\
+ & 10^{-3}\end{array}$ & + \\
\hline $10^{-8}$ & $9 / 1$ & $\begin{array}{r}4 \\
25 \\
37\end{array}$ & $\begin{array}{l}1 \\
1 \\
1\end{array}$ & $\begin{array}{l}\mathrm{NaCl} \\
\mathrm{NaCl} \\
\mathrm{NaCl}\end{array}$ & $\begin{array}{ll}+ & 10^{-1} \\
+ & 10^{-3} \\
- & \end{array}$ & $\begin{array}{l}+ \\
+\end{array}$ \\
\hline $10^{-8}$ & $9 / 1$ & $\begin{array}{r}4 \\
25 \\
37\end{array}$ & $\begin{array}{l}2 \\
2 \\
2\end{array}$ & $\begin{array}{l}\mathrm{NaCl} \\
\mathrm{NaCl} \\
\mathrm{NaCl}\end{array}$ & $\begin{array}{ll}+ & 10^{-2} \\
+ & 10^{-3} \\
+ & 10^{-3}\end{array}$ & $\begin{array}{l}+ \\
+ \\
+\end{array}$ \\
\hline $10^{-9}$ & $9 / 1$ & $\begin{array}{r}4 \\
25 \\
37\end{array}$ & $\begin{array}{l}2 \\
2 \\
2\end{array}$ & $\begin{array}{l}\mathrm{NaCl} \\
\mathrm{NaCl} \\
\mathrm{NaCl}\end{array}$ & $\begin{array}{ll}+ & 10^{-2} \\
+ & 10^{-2} \\
+ & 10^{-3}\end{array}$ & $\begin{array}{l}+ \\
+ \\
+\end{array}$ \\
\hline
\end{tabular}

Nous pouvons conclure que l'extraction la plus efficace est faite à $25^{\circ}$ ou $37^{\circ}$ pendant 2 heures. Cependant il y a une chute importante du titre par rapport au virus initial.

\section{Action de la RNA-ase sur l'acide nucléique}

L'addition de RNA-ase à deux stades de la préparation a donné les résultats suivants: 
IABLEAU $N^{\circ} V I I$

Infectiosité de 1 'acide nucléique traité et non traitê par la RNA-ase (effet cytopathogène sur cellules rénales de porc)

\begin{tabular}{|c|c|c|c|c|c|c|c|c|c|c|c|}
\hline \multicolumn{3}{|c|}{$\begin{array}{c}\text { Acide nucléique } \\
\text { (non traftê) en } \\
\text { solution hypertonique. } \\
\text { Têmoin d'infectiositê } \\
\text { de l'extrait }\end{array}$} & \multicolumn{3}{|c|}{$\begin{array}{l}\text { Acide nucléique (non } \\
\text { traitê) en solution } \\
\text { hypertonique portê } 30 \mathrm{~mm} \\
\text { à } 37^{\circ} \text {. Conservation de } \\
1^{\prime} \text { infectiosité }\end{array}$} & \multicolumn{3}{|c|}{$\begin{array}{l}\text { Acide nucléique en } \\
\text { solution hypertonique } \\
\text { traitê par la RNA-ase } \\
1 \mathrm{mg} / \mathrm{ml}-30 \mathrm{mn} \text { à } 37^{\circ}\end{array}$} & \multicolumn{3}{|c|}{$\begin{array}{l}\text { Extrait nucléique aqueux } \\
\text { traitể a la HNA-ase } \\
1 \mathrm{mg} / \mathrm{ml}-30 \mathrm{mn} \text { à } 37^{\circ}\end{array}$} \\
\hline $10^{-1}$ & $10^{-2}$ & $10^{-3}$ & $10^{-1}$ & $10^{-2}$ & $10^{-3}$ & $10^{-1}$ & $10^{-2}$ & $10^{-3}$ & $10^{-1}$ & $10^{-2}$ & $10^{-3}$ \\
\hline+ & + & - & + & + & - & - & - & - & - & - & - \\
\hline $\begin{array}{c}\text { Zè p. } \\
+\end{array}$ & $\begin{array}{c}2 \text { ẽ } \mathrm{p} . \\
+\end{array}$ & 2è $\mathrm{p}$. & $\begin{array}{c}\text { 2è } p . \\
+\end{array}$ & $\begin{array}{c}2 \pi \mathrm{e} p . \\
+\end{array}$ & 2ẽ p, & 2ё p. & 2è $p$. & 2 è $\mathrm{p}$. & 2è $\mathrm{p}$. & 2ѐ p. & 2è p. \\
\hline
\end{tabular}

De ce tableau, il ressort que :

- La RNA-ase inactive l'extrait nucléique aussi bien au stade d'extrait aqueux qu'en solution hypertonique (dans les conditions de l'expérience, c'est-à-dire avec une forte concentration de RNA-ase - $1 \mathrm{mg} / \mathrm{ml}$;

- L'acide nucléique du virus local est donc de l'ARN; ce qui est en accord avec les résultats obtenus par les méthodes d'inhibition chimique;

- l'ARN en solution hypertonique paraît assez stable puisqu'il résiste 30 minutes à $37^{\circ}$.

\section{Caractérisation histochimique intracellulaire du virus}

- Vert de méthyle-pyronine et test de BRACHET.

Les cellules témoins non infectées, colorées au vert de méthyle-pyronine, présentent un cytoplasme rose, un noyau vert, et la chromatine n'y est pas apparente. Les cellules infectées ont un cytoplasme nettement plus rouge: leurs noyaux verts sont souvent pycnotiques, et la chromatine y apparaît granuleuse.

Après traitement à la RNA-ase et coloration. les cellules témoins présentent encore un noyau vert, mais leur cytoplasme n'est plus coloré. Pour les cellules infectées, l'aspect du noyau est le même qu'après coloration directe sans action de la RNA-ase. Par contre leur cytoplasme est très faiblement coloré en rose.

En conclusion, le noyau coloré en vert contient l'ADN, et l'ARN coloré en rouge ou rose est localisé au cytoplasme. L'action de la RNA-ase démontre bien la localisation cytoplasmique de l'ARN. Les cellules infectées contiennent davantage d'ARN que le témoin (coloration plus intense), ce qui correspondrait à la présence du virus dans le cytoplasme.

- Feulgen.

Les noyaux sont colorés en rouge, les cytoplasmes ne sont pas colorés, aussi bien pour les cellules infectées que témoins. Ce qui prouve qu'il n'y a pas d'ADN, décelable par cette réaction, dans le cytoplasme.

\section{- Orangé d'acridine.}

L'examen en lumière U.V. montre les noyaux verts, et les cytoplasmes ainsi que les nucléoles orangés ou rouge orangé. Le cytoplasme des cellules infectées apparaît plus rouge vif, ce qui indique la présence d’une plus grande quantité d'ARN, correspondant au virus.

\section{CONCLUSIONS}

Le virus de l'encéphalomyélite porcine malgache présente un certain nombre de propriétés physico-chimiques qui l'apparentent aux souches européennes de la maladie de Teschen et qui imposent de lc classer parmi les entérovirus du porc:

- sa petite taille, inférieure à $50 \mathrm{mu}$;

- il contient de l'ARN;

- il résiste aux solvants organiques, notamment au chloroforme. Il n'a donc pas de lipides essentiels;

- de plus, il résiste à l'acidité du milieu (pH 3).

Ces critères sont, en effet, ceux retenus pour établir qu'un virus appartient au groupe des Entérovirus (6). 
D'ailleurs d'autres caractères le rapprochent aussi des Entérovirus et, parmi eux, du virus de Teschen européen:

- stabilisation par le chlorure de magnésium vis-à-vis de la chaleur;

- résistance au désoxycholate de soude;

- résistance à la trypsine;

- inhibition par le 5 Fluoro-uracile (comme le poliovirus);

- biosynthèse cytoplasmique.

Nous pensons donc que le virus local présente les caractères physico-chimiques d'un entéro-virus porcin, et qu'il est très proche du virus de Teschen. L'étude des propriétés biologiques sera à faire pour confirmer cette parenté.

\section{SUMMARY}

Studies on some physical and chemical properties of the swine encephalomyelitis virus of Madagascar

Some properties of the malagasy swine encephalomyelitis virus were studied comparatively with czechoslovaks strains.

Small size, ribonucleic acid, insensitivity to chloroform and acid $\mathrm{pH}$, heat stabilization by magnesium chloride, insensibility to sodium desoxy cholate and trypsin, inhibition by 5 fluorouracil and intracellular multiplication are identical.

\section{RESUMEN}

Estudio de algunas propiedades fisico-quimicas del virus de la encefalomielitis del cerdo malgacho

Se estudian varias propiedades del virus de la encefalomielitis del cerdo malgacho, en comparación con las de las cepas checas. Pequeño tamaño, ácido ribonucléico, resistencia para con los disolventes orgánicos y los pH ácidos, estabilización por el cloruro de magnesio, resistencia al desaxicloato de sodio y a la tripsina, inhibición por el 5 fluoruracilo y síntesis citoplasmica son identicos.

\section{BIBLIOGRAPHIE}

1. ANDREWES (C.H.) et HORSTMAN (D. M.), " The susceptibility of viruses to ethyl ether », J. gen. Microbiol. 1949, $3: 290-97$.

2. BETTS (A. O.), * Porcine Enterovirus », in $A d v$. vet. Sci. 1964, 9: 225-49. N.Y. USA. Academ1c Press.

3. BOURDIN (P.) et collab., "Culture du virus de Teschen sur cellules épithéliales de rein de porc en couche monocellulaire», Ann. Inst. Pasieur, Paris, 1957, 93 (5): 581-91.

4. BOURDIN (P.), SERRES (H.) et RASOLOFOMANANA (P.), " Mise au point d'un vaccin nasal contre l'encéphalomyélite porcine malgache ", Rev. Elev. Méd. vét. Pays trop., 1966, 19 (2) : 119-30.

5. BUCZEK (J.), «Further characterization of bovine enteroviruses isolated in Poland $x$, Arch. ges. Virusforsch., 1970, 30: 408-10.

6. Comité des Entérovirus: Virology, 1962, 16: 50104 - Virology, 1963, 19: 114-16 - Science, 1963, 141: 153.

7. CROWTHER (D.) et MELNICK (J. L.), « Studies of the inhibitory action of guanidine on poliovirus multiplication in cell cultures $»$, Virology, 1961, 15: $65-74$.

8. DARDIRI (A. H.), DELAY (P. D.) et BACHRACH (H. L.), "Effect of 2 ( $\alpha$ Hydroxybenzyl) benzimidazole on Teschen disease virus, pig enteric viruses, and foot and mouth disease virus in kidney cell cultures , Can. J. comp. Med., 1964, 28: 161.

9. EGGERS (H. J.) et TAMM (I.), « On the mechanism of selective inhibition of enterovirus multiplication by 2-๔ H.B.B. », Virology 1962, 18: 426-38.

10. HAHNEFELD (H.) et Collab., «Talfan disease der Schweine in Deutschland 2. Mitteilung: weitere charakterisierung des kulturvirus », Arch. exp. Vet. Med., 1966, 20, 1293.

11. LARENAUDIE (B.), HAAG (J.) et CARNERO (R.), «La purification du virus de la peste porcine africaine par le Fluoro-carbone », Bull. Off. int. Epizoot., 1965, 63 (5-6) : 711-16.

12. LEPINE (P.) et ATANASIU (P.), « Existence à Madagascar de l'encéphalomyélite enzootique des porcs. Immunité croisée avec le virus de la maladie de Teschen. Transmission au sanglier,$A n$ nls. Inst. Pasteur, Paris, 1950, 79 (2) : 113-20.

13. LEPINE (P.), «Techniques de laboratoire en virologie humaine $*$ Paris, Masson, 1964.

14. MARAMOROSCH (K.) et KOPROWSKI (H.), "Methods in virology", New York, Academic Press, 1967. T. П.

15. MAYR (A.) et BÖGEL (K), «Der Chloroform Resistenstest zur Isolierung und characterizierung von Enteroviren », Zentbl. Bakt, Parasitkde I. 1961, 182: 564-70. 
16. MAYR (A.), «The virus of Teschen disease $»$, Ann. N.Y. Acad. Sci., 1962, 101: 423-27.

17. MUNYON (W.) et SALZMAN (N.P.), «The incorporation of 5-FU into poliovirus 》Virology, $1962,18: 95.101$.

18. PORTOCALA (R.), SAMUEL (I.) et POPESCU (M.), «Effect of lyophilisation on picornaviruses ", Arch. ges. Virusforsch., 1969, 28 : 97-99.

19. PORTOLANI (M.), BERNARDINI (A.) et LA PLACA (B.), "On the susceptibility of bovine enteroviruses to the inhibitory action of guanidine and $2 \alpha$ (H.B.B.) », Vet. itol., 1968, $19: 76-81$ (Vet. Bull., 1968, 38 (10) : 688. Analyse $\pi^{\circ} 4104$ ).

20. RASMUSSEN (P. G.), «A study of enteroviruses in Danish pigs - IV - effect of cations on thermal inactivation, and of $2 \alpha$ (H.B.B.) on virus propagation in cell culture ", Nord. Vet. Med., 1969, 21 : 449-53. (Vet. Bull., 1970, 40 (3): 196. Analyse $\Pi^{\circ}$ 1134).

21. SALZMAN (N. P.), "The rate of formation of vaccinia deoxyribonucleic acid and yaccinia virus », Virology, 1960, $10: 150-52$.

22. STROHMAIER (K), «Vergleichende Untersuchungen Der Infektiösen Ribonucleicsaïre Des Virus Der Ansteckende Schweinelahmung (Teschener Krankheit) Mit Hochmolekularer Gewebe Ribonucleicsaiire n, Z. Naturf., 1963, 18 : 788-98.

23. WALLIS (C.) et MELNICK (J.L.), «Cationic stabilization - A new property of enteroviruses $n$, Virology, 1962, 16: 504-06. 